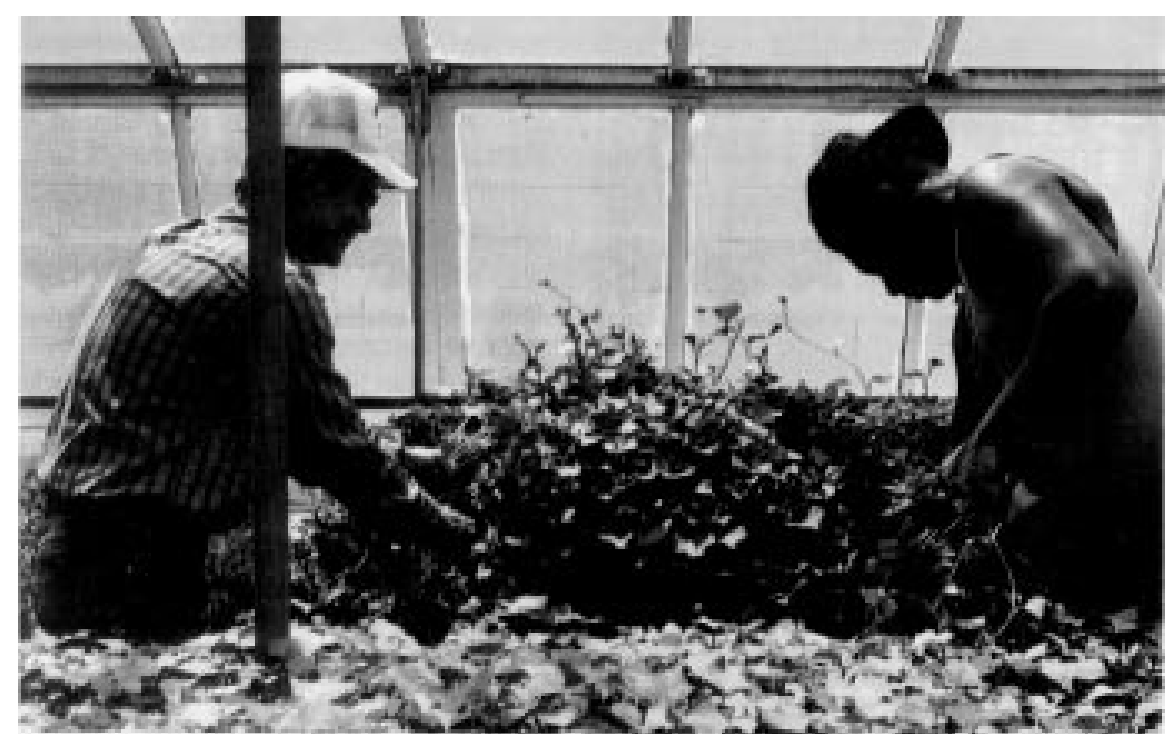

Fig. 4. Greenhouse cutting of foundation plants for field transplanting.

The foundation seedstock are stored in temperature-controlled storage rooms. The seedstock are cured for 5 to 7 days at 85 to $90 \mathrm{~F}$ with a relative humidity $(\mathrm{RH})$ of $85 \%$ to $90 \%$. They arekept at $60 \mathrm{~F}$ with a $\mathrm{RH}$ of $70 \%$ for the remainder of the storage period.

In January, immediately prior to packing seedstock, the Louisiana Dept. of Agriculture conducts a storage inspection to ensure seed quality and purity. All seedstock is run over a conveyor, where roots that have visible mutations, are diseased are and off-size are removed. Acceptable seedstock is packed in 40-lb (18-kg) cardboard boxes for distribution.

After harvest, estimate of each variety's seedstock that will beavailablefor Louisianagrow- ers is provided to cooperative extension agents. Individual agents process orders from the growers of their respective parish. University research and extension personnel prorate the seedstock to the parishes. When available seedstock supplies exceed the state's total seed requirements, sales are made to out-of-state growers.

The varieties that are being maintained at present in the Louisiana sweetpotato foundation seed program include: 'Beauregard', 'Hernandez', 'Travis', 'Jewel', 'Centennial', 'Darby', and thebreeding line 'L86-33'. Several older cultivars, including 'Porto Rico', 'Heartogold', and 'Goldrush' are maintained in small quantities for use in the LSU breeding nurseries.

\section{Mississippi Sweetpotato Foundation Seed Program}

\author{
R. Orofton Sloan, Jr.
}

Additional index words. Ipomoea batatas

(L.) Lam., flesh discolorations, somatic

mutations, chimera, mutation

Summary. The sweetpotato foundation seed program in Mississippi is committed to producing and supplying high-quality sweetpotato seed to the Mississippi sweetpotato industry. In 1991, a study was initiated to evaluate the effects of small heteroclinal chimeras in foundation seed roots on the root flesh quality in subsequent generations. The presence of small heteroclinal chimeras in parent seed roots did not increase the number or size of chimeras in three subsequent generations of storage roots.

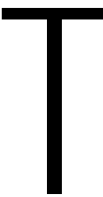

he sweetpotato foundation seed program began in Mississippi in 1962, when the varieties Centennial, Goldrush, and Porto Rico were certified by the Mississippi Seed Improvement Assn. The foundation seed program, administered by the Mississippi Agricultural and Forestry Experiment Station, was located at the Pontotoc Branch Station and designed to produce foundation seed for sale to certified sweetpotato seed growers for production of registered and certified seed for the Mississippi sweetpotato industry.

At present, the foundation seed program, sweetpotato production research, and aspects of the sweetpotato breeding program are located at the Pontotoc Research and Extension Center (PREC) because it is located within 30 miles of the major sweetpotato production areas in Mississippi. 'Beauregard' accounts for $95 \%$ of the foun-

Pontotoc Research and Extension Center, Route 4, Box 249, Ponotoc, MS 38863.

The cost of publishing this paper was defrayed in part by the payment of page charges. Under postal regulations, this paper therefore must be hereby marked advertisement solely to indicate this fact. 
dation seed production; an increased planting of 'Hernandez' is planned for 1994 and decreased plantings of 'Nancy Hall', 'Jewel', and 'Centennial'. Certified seed producers no longer buy foundation seed from the station to produce registered and certified seed to sell to the farmers. Farmers buy foundation seed directly from PREC and then produce their own seed.

Hill selections are made from the foundation plantings based on superior yield, shape, and skin color. After curing, the hill selections are stored in 1-bushel crates in a well-ventilated storage house maintained at $60 \mathrm{~F}(15.5 \mathrm{C})$ until presprouting before bedding.

After the storage roots are presprouted and before the roots are bedded, they are sliced transversely on the distal end into 1/8-inch (3.2-mm) slices. The slicing is conducted for several reasons. It is well-documented that cutting reduces proximal dominance and increases sprout production (Kushman, 1970). Also, the roots are examined for disease, flesh color, and internal flesh color mutations. These somatic mutations vary in size, location in the root, and intensity of discoloration (Fig. 1) (Edmond, 1971).

Somatic mutations of storage root skin color range from periclinal chimeras, where the entire skin surface differs from the characteristic color of the variety, to mericlinal chimeras, whereasection or strip of the skin or periderm differs in color.

On storage roots exhibiting mericlinal chimeras with stripes of white on ayellow skin, plants arising from the white stripes produced whiteskinned roots and plants arising from the yellow stripes produced yellow-skinned roots (Rosa,
1926). Mericlinal chimeras often indicatethepresence of sectorial chimeras in the storage root flesh (Hernandez, 1956).

Because plants arising from buds on a sectorial chimera produce roots that have the same characteristics as the chimera, seed roots with mericlinal and sectorial chimeras are discarded.

Because the large-sized chimeras havebeen shown to produce plants that in turn produce roots with increased levels of mutations, the Mississippi sweetpotato foundation seed program, in an effort to producehigh-quality seed, discarded seed roots with smaller heteroclinal chimeras from the foundation program.

In 1991, the Mississippi sweetpotato foundation seed program was discarding $>50 \%$ of the "Beauregard" storage roots saved as hill selections because of the presence of heteroclinal chimeras. Many of these chimeras were small, $<1 / 8$ of an inch $(3.2 \mathrm{~mm})$ in diameter. This effort to increase seed quality greatly reduced the production of foundation seed because the resulting number of bedded seed was small.

In 1991, a study was initiated to determine if small flesh discolorations were passed on to successive generations of storage roots and whether they increased in number or enlarged in size. Onehundred-twenty-seven seed roots that had been discarded from the foundation seed program because of heteroclinal chimeras were bedded in sawdust plant beds. After the plants had sprouted and grown to a size large enough to transplant in the field, the seed root with the plants attached was pulled up. The root and the corresponding plants were labeled. The seed root was cut transversely

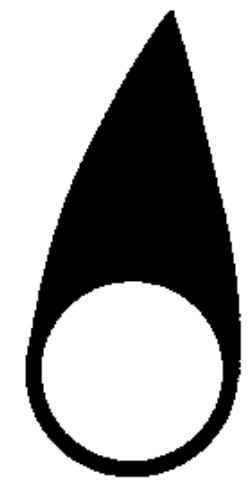

1. PERKELINAL

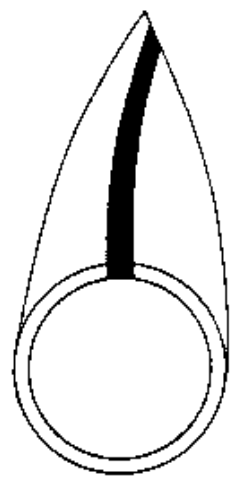

2. MERICLINAL

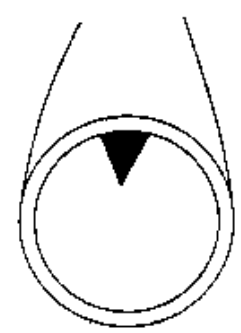

3. SECTORIAL
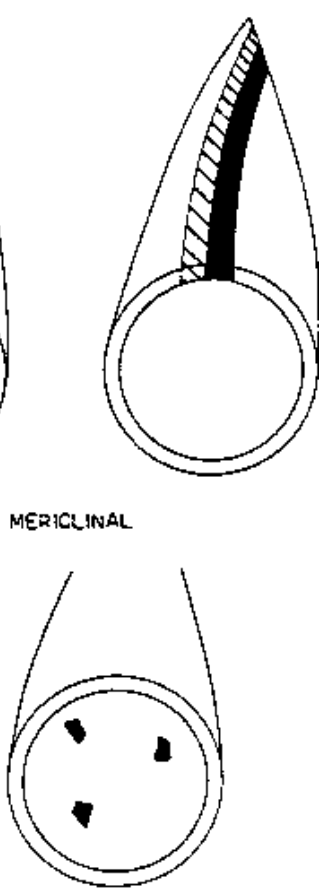

4. HETEROCLINAL

Fig. 1. Types of chimeras in storage roots (Edmond, 1971).

into 1/8-inch (3.2-mm) slices. The number and size of discolored spots on each slice were re corded. A rating system (1-5) was designed so that a numerical value could be assigned to the different sizes of discolored spots (Fig. 2). Each spot on each slice was rated and recorded. For example, a single root might be cut into 50 slices. Three of the slices had two of the smallest spots (rating $=1$ ) and also had one of the largest spots (rating $=5)$. The rating for that root would be $(3$ * 1) $+(3 * 1)+(3 * 5)=21$.

The plants were planted in the field, grown using standard cultural practices, and harvested in Oct. 1991. One root from each plant was saved to bed in 1992. The remaining roots were cut transversely into 1/8-inch $(3.2-\mathrm{mm})$ slices, and the number and size of any discolored spots were recorded.

To maintain manageable root numbers, representative progeny from the original roots were chosen to continue the study in 1992 and 1993. The original parent roots were divided into three categories; high (degree 3), medium (degree 2), and low (degree 1); based on the number and severity of the chimeras found in the root flesh. In the three categories, roots with a total rating of 0 to 2 were classified as low (degree 1 ), a total rating of 6 to 8 were classified as medium (degree 2), and a total rating of 12 to 32 was classified as high (degree 3). Two parent roots were chosen from each category, and the progeny from those parent roots were used for the 1992 and 1993 evaluations. Also included in the 1992 and 1993 trials were plants from the foundation program plant beds. These were plants grown from foundation seed determined to be free from flesh discolorations. The 1992 and 1993 trials were planted in a randomized complete-block design. In 1992, at harvest, one root was reserved from each plant to bed the following year. The other roots were cut transversely into 1/8-inch (3.2-mm) slices and discolored spots were counted and rated. The same procedure was followed in 1993.

Regression analysis showed that there was notalinear relationship between the degree of total mutation from one generation of storage roots to the next (Table 1). Contrasts $(P=0.05)$ were used to compare total mutations in the storage roots grown from foundation seed to total mutations in roots that were descendents of the original parent roots discarded from the foundation seed program in 1991. There were no significant differences in total storage root mutations in 1992 and 1993 between progeny of foundation seed and progeny of seed discarded from the foundation program in 1991.

Concern about discarding large amounts of foundation seed prior to bedding because of the presence of small heteroclinal chimeras provided the impetus to initiate the study. It appears that the presence of the small ( $<3 \mathrm{~mm}$ in diameter) discolored spots does not lead to an increase in the number of flesh mutations or an increase in the 


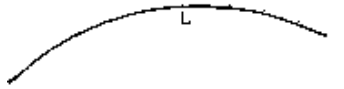

1

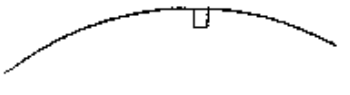

2

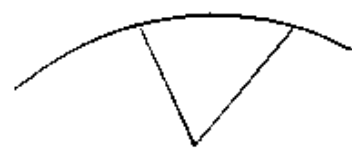

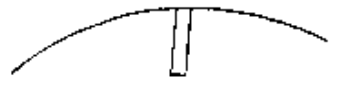

3
4

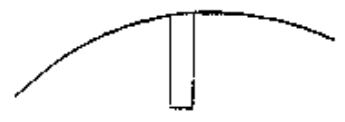

Fig. 2. Chimera rating scale.

Table 1. Simple linear regression analysis slope estimates for total mutations between three generations of sweetpotato storage roots.

\begin{tabular}{|c|c|c|c|c|}
\hline \multicolumn{2}{|l|}{ Model } & $\begin{array}{c}\text { Slope } \\
\text { estimate ( }(\mathrm{SE})\end{array}$ & Prob $>|\mathrm{T}|$ & $r^{2}$ \\
\hline $\begin{array}{l}\text { Total } \\
\text { mutations }\end{array}$ & $\begin{array}{ll} & \text { Total } \\
\text { s } & \text { mutations }\end{array}$ & & & \\
\hline 1991 & $=1992^{z}$ & $-0.0280 \pm 0.0335$ & 0.4226 & 0.0653 \\
\hline $\begin{array}{l}\text { Total } \\
\text { mutations }\end{array}$ & $\begin{array}{ll} & \text { Total } \\
\text { s } & \text { mutations }\end{array}$ & & & \\
\hline $1992=$ & $=1993^{2}$ & $-0.00144 \pm 0.0073$ & 0.8494 & 0.0012 \\
\hline
\end{tabular}

size of the mutations.

TheMississippi sweetpotato foundation program will continue to slice each seed root selected for bedding. Each root will be examined for flesh color, pests, diseases, and thepresence of somatic mutations in the flesh color. However, the small spots that caused the seed root to be rejected in previous years will not cause the rejection of the seed root beginning in 1994.

\section{Literature Cited}

Edmond, J.B. 1971. Sweet potato: Production, processing, marketing. p. 62-64.
Hernandez, T. P., J.J. Mikell, T. Hernandez, and J.F. Fontenot. 1956. Mutations, a means of improving sweet potato varieties. Proc. Assn. Southern Agr. Workers 53:175.

Kushman, L.J., W.D. Drinkwater, and B. Graves. 1970. Plant production. Thirty years of Cooperative sweet potato research. 1939-1969. Louisiana Agr. Exp. Sta., Southern Coop. Ser., Bul. 159:1824.

Rosa, J.T. 1926. Mutations in sweet potatoes. J. Hered. 17:167-168.

\section{The Certified Sweetpotato Seed Program in North Carolina}

\author{
Jonathan R. Schultheis ${ }^{1}$, \\ Carroll E Collins ${ }^{2}$, and \\ Charles W. Averre ${ }^{3}$
}

Additional index words. Ipomoea batatas, breeder seed, foundation seed, registered seed, russet crack, disease, pathogen, feathery mottle virus, micropropagation, virus-indexed

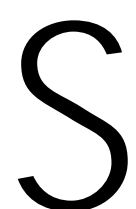

weetpotato is the most valuable vegetable crop produced in North Carolina, having farm gatereturns of about \$40 million in 1992 (North Carolina Agricultural Statistics, 1993). The certified sweetpotato seed program in North Carolinaserves alargeindustry to providehigh-quality seed of varieties that aretrue-to-type and freefrom pests. This program annually includes 700 acres and provides more than 150,000 bushels of seed roots. Certified seed helps maximize root quality such as shape and skin and flesh color, while also providing the opportunity to achieve high yields

As new varieties are developed and released by the North Carolina Agricultural Research Service (NCARS) and other breeding programs, they must be increased carefully to maintain desirable characteristics initially developed by the plant breeder. At the same time, established varieties

North Carolina State University, Raleigh, NC 27695.

${ }^{\top}$ Assistant Professor and Vegetable Specialist, Dept. of Horticultural Science.

${ }^{2}$ Director, North Carolina Crop Improvement Assn.

3Professor and Plant Pathologist, Plant Pathology Dept.

This research was funded in part by the North Carolina Agricultural Research Service (NCARS Project No. NC6187) Raleigh, NC 27695-7643, and the North Carolina Sweetpotato Certified Seed Producers' Assn. We gratefully acknowledge the assistance of W.R. Jester (Area Specialized Agent) and the technical assistance of D.E. Adams and J.G. Driver. The cost of publishing this paper was defrayed in part by the payment of page charges. Under postal regulations, this paper therefore must be hereby marked advertisement solely to indicate this fact. 